\title{
Smart Water Dispenser Terintegrasi untuk Monitoring Konsumsi Air Minum Harian
}

\author{
Deni Ariyanto Abadi, Laurentius Kuncoro Probo Saputra*, Gloria Virginia \\ Fakultas Teknologi Informasi, Informatika, Universitas Kristen Duta Wacana, Yogyakarta, Indonesia \\ Email: ${ }^{1}$ deni.abadi@ti.ukdw.ac.id, 2,"kuncoro@staff.ukdw.ac.id, ${ }^{3}$ virginia@staff.ukdw.ac.id \\ Email Penulis Korespondensi: kuncoro@staff.ukdw.ac.id
}

\begin{abstract}
Abstrak-Kekurangan air dapat menyebabkan permasalahan kesehatan yang sangat serius. Realitas di lapangan, bahwa sebagian orang mengatakan bahwa mereka tidak mengetahui jumlah air yang harus mereka penuhi setiap harinya. Untuk mengetahui tingkat kebutuhan air yang ideal bagi tubuh perlu melibatkan ahli gizi atau pakar kesehatan karena banyak faktor yang mempengaruhi tingkat kebutuhan air yang harus dikonsumsi setiap harinya. Tentu saja bila melibatkan atau berkonsultasi dengan pakar kesehatan memerlukan biaya yang tidak sedikit. Untuk mengatasi permasalahan tersebut, diperlukan adanya sebuah sistem perangkat yang saling terintegrasi dan memiliki kemampuan untuk menentukan tingkat kebutuhan air yang ideal bagi tubuh pengguna sesuai dengan faktor-faktor yang mempengaruhi tingkat kebutuhan air tersebut serta mampu mengingatkan pengguna agar tetap mencukupi kebutuhan airnya. Sistem smart water dispenser yang dibangun berbasis IoT sehingga dapat terintegrasi dengan aplikasi android dan cloud server menjadi satu kesatuan sistem dapat digunakan dalam membantu memecahkan permasalahan tersebut. Sistem yang dibangun memiliki basis pengetahuan yang diperoleh dari tenaga profesional untuk menentukan kebutuhan ideal kebutuhan air minum harian pengguna. Sebagai basis pengetahuan, perhitungan kebutuhan air menggunakan kuesioner GPPAQ dan Estimated Energy Requirement (EER). Basis pengetahuan ini diimplementasikan pada aplikasi android, dan aplikasi ini dapat berkomunikasi dengan perangkat water dispenser untuk mencatat kebutuhan air minum harian yang telah diambil serta mengingatkan pengguna jika kebutuhan ideal belum tercapai. Berdasarkan hasil implementasi dan pengujian, sistem telah mampu menghitung tingkat kebutuhan air pengguna berdasarkan faktor tingkat aktivitas fisik, umur, dan berat badan. Sistem water dispenser memiliki akurasi pencatatan jumlah air yang dikeluarkan sebesar $92,6 \%$, sehingga terjadi selisih perhitungan di dalam aplikasi android terhadap jumlah air yang diambil pengguna dari water dispenser.
\end{abstract}

Kata Kunci: Smart Water Dispenser; Internet of Things; Konsumsi Air Minum; Monitoring Kebutuhan Air; Aktifitas Fisik

Abstract-Lack of water can cause serious health problems. In reality, some people do not know the amount of water they must drink daily. It's hard to find out the daily water intake needs because it is affected by a lot of things and it will be better to involve a nutritionist or health expert to get the best amount, which may require extra cost. To overcome these problems, it is necessary to have a system that is incorporated in an integrated system with the ability to calculate the ideal level of water needs for the body according to factors that affect the level of water needs and able to remind users to keep their daily needs. IoT-based smart water dispensers that can be integrated with android applications and cloud servers into a single system can be used to help solve these problems. The system has a knowledge base obtained from professionals to determine user water consumption. The system calculates the water consumption using the GPPAQ questioner and Estimated Energy Requirement (EER) formula. The base knowledge is implemented on Android applications, and this application can track the amount of water that has been consumed by the user. The test results show that the system can calculate the amount of water demand based on some factors such as the level of physical activity, age, and body weight. The water dispenser system has an accuracy of recording the amount of air released by $92.6 \%$, so there is a difference in the calculation in the Android application to the amount of air that the user takes from the water dispenser.

Keywords: Smart Water Dispenser; Internet of Things; Mineral Water, Water Consumption Monitoring; Physical Activity Level

\section{PENDAHULUAN}

Peduli akan kesehatan adalah kewajiban setiap individu mengingat banyaknya jenis penyakit yang berkembang saat ini, salah satunya adalah dengan mencukupi kebutuhan air dalam tubuh. Kekurangan air dapat menyebabkan permasalahan kesehatan yang sangat serius, seperti meningkatnya resiko kerusakan ginjal [1]. Konsumsi air yang cukup dapat menjaga kesegaran dan kebugaran jasmani dalam memenuhi $70 \%$ bagian tubuh yang diketahui berbentuk cairan [2]. Berdasarkan survei yang dilakukan oleh Onepoll, dua pertiga dari mereka mengatakan terlalu sibuk untuk sekedar minum air, dan satu dari lima orang mengatakan bahwa tidak tahu berapa banyak air yang harus mereka konsumsi. Survey juga telah dilakukan kepada sejumlah mahasiswa Universitas Kristen Duta Wacana. Hasil survey memperlihatkan bahwa 23\% mengaku bahwa mereka tidak mengetahui jumlah air yang mereka butuhkan per-harinya, 15,1\% mengatakan hanya mengkonsumsi kurang dari satu liter air, dan sisanya 53,4\% mengakui mengkonsumsi air lebih dari satu liter dan kurang dari dua liter perharinya. Sedangkan menurut riset yang dipublikasikan oleh European Journal of Nutrition, 25\% orang di Indonesia tidak memenuhi standar jumlah air yang harus dikonsumsi setiap harinya [3]. Untuk mengetahui tingkat kebutuhan air yang ideal bagi tubuh perlu melibatkan ahli gizi atau pakar kesehatan karena banyak faktor yang mempengaruhi tingkat kebutuhan air yang harus dikonsumsi setiap harinya, layaknya seperti atlet yang selalu harus selalu terawasi [4]. Tentu saja bila melibatkan atau berkonsultasi dengan pakar kesehatan memerlukan biaya yang tidak sedikit. 
Penyelesaian tentang permasalahan kebutuhan air minum telah dilakukan oleh beberapa penelitian sebelumnya, terutama pada pengembangan automatic water dispenser. Sebuah mesin yang dapat secara otomatis berhenti mengisi jika air pada gelas/ botol sudah hampir penuh[5]-[8]. Fathoni dkk. [8] berfokus pada penggunaan mesin water dispenser bagi pengguna tuna netra. Sehingga pengguna tuna netra tidak perlu khawatir jika gelas atau botol terisi air hingga luber. Secara umum, sensor yang digunakan ialah sensor ultrasonic untuk mendeteksi level ketinggian air pada gelas/ botol. Anuradha dkk. [7] meningkatkan kemampuan mesin tersebut agar dapat mengirimkan pemberitahuan kepada aplikasi android pengelola apabila air pada akan segera habis. Implementasi sistem ini didukung dengan adanya teknologi IoT saat ini dengan integrasi mesin dengan cloud dan aplikasi perangkat mobile, sehingga sistem yang dikembangkan dapat menyelesaikan permasalahan pada sisi pengelola mesin di tempat umum [9]. Optimalisasi kebutuhan daya listri dari mesin juga menjadi fokus penelitian. Tujuannya ialah bagaiamana mesin dapat menggunakan daya listrik sesuai kebutuhan sehingga penghematan penggunaan listrik dapat dilakukan, seperti pada penelitian Chen dkk. [10], Benny dkk. [11], dan Cheng dkk. [12].

Gagasan Internet of Things (IoT) telah diakui sebagai inovasi yang dapat meresap dalam kehidupan untuk memenuhi kebutuhan dan mempermudah pekerjaan. IoT menjadi salah satu teknologi yang mengoptimalisasi alat dengan media sensor, radio frequency identification, wireless sensor network dan media cerdas lainnya yang memungkinkan pengguna dapat berinteraksi dengan semua peralatan yang terhubung dalam jaringan [13]. IoT dapat diterapkan pada peralatan rumah tangga [14], otomasi industri, insfrastruktur perkotaan, dan sebagainya sebagai suatu sistem yang dapat membantu melakukan monitoring secara menyeluruh.

Penyelesaian permasalahan lainnya dari sisi pengguna sistem yaitu bagaimana sebuah smart water dispenser dapat mengetahui kebutuhan konsumsi air minum yang ideal dari penggunanya dan dapat melakukan pencatatan jumlah air minum yang telah dikonsumsi di setiap harinya. Kebutuhan konsumsi air minum pengguna, dapat ditentukan melalui tingkat aktivitas fisik pengguna. Proses menentukan tingkat aktivitas fisik menurut Ainsworth [15] dapat dilakukan secara langsung maupun tidak langsung. Pengukuran secara langsung dilakukan dengan menggunakan sensor gerakan seperti sensor accelerometer atau spedometer. Sedangkan pengukuran secara tidak langsung dilakukan dengan menggunakan record atau logbooks dan juga dapat dalam bentuk kuisioner, sehingga biaya yang dibutuhkan pada proses pengukuruan tangkat aktivitas akan jauh lebih rendah dibandingkan dengan pengukuran secara langsung. Salah satu kuesioner yang dapat digunakan ialah kuesioner General Practice Physical Activity Questionnaire (GPPAQ) [16]. GPPAQ merupakan salah satu metode pengukuran tingkat aktivitas fisik yang awalnya didesain untuk dilakukan di praktek dokter terutama pada primary care clinic [17]. Kuisioner GPPAQ didesain sangat sederhana dikarenakan untuk pasien yang sedang menunggu antrean praktek dokter sebagai metode screening dan bukan untuk penilaian secara detail meskipun sudah memberikan hasil yang cukup reliable. Pemilihan kuisioner ini berdasarkan pada rendahnya tingkat kerumitan kuisioner. Hal ini dikarenakan kuisioner tersebut dapat digunakan oleh pengguna tidak hanya sekali melainkan setiap beberapa waktu secara berkala untuk meminimalisir adanya perubahan level aktivitas fisik yang terjadi pada pengguna, oleh karena itu pemilihan kuisioner yang mudah dipahami diharapkan meminimalisir kemungkinan terjadinya drop-out atau kurangnya minat pengguna dalam mengisi kuisioner. Meski demikian, GPPAQ hanya diperuntukan bagi pengguna berumur 16-74 tahun, dimana pada usia di luar 1674 tahun dapat mempengaruhi validitas dari hasil kuisioner. Namun, Ahmad et.al [17] menyatakan bahwa GPPAQ memiliki validitas yang rendah pada pengguna atau responden berusia 60-74 tahun saat dibandingkan dengan pengukuran objektif menggunakan alat accelerometry. Berdasarkan hal tersebut, batasan usia pengguna pada penelitian ini adalah 16-60 tahun. Setelah tingkat aktivitas dapat diketahui berdasarkan kuisioner GPPAQ, maka perhitungan kebutuhan air yang ideal bagi tubuh dapat dilakukan dengan menghitung Estimated Energy Requirement (EER) atau estimasi kebutuhan kalori harian.

Sehingga pada penelitian ini mengembangkan sebuah sistem smart water dispenser sebagai alat bantu pengguna dalam memenuhi kebutuhan air minum hariannya. Konsep smart pada perangkat smart water dispenser berbasis IoT yang akan dibangun ini adalah perangkat mampu terintegrasi dengan aplikasi android dan cloud server menjadi satu kesatuan sistem untuk melakukan pengisian air secara otomatis tanpa perlu mengetahui batas kapasitas maksimal pada botol minum pengguna atau secara manual sesuai dengan keinginan pengguna. Sistem juga mampu menentukan tingkat kebutuhan air yang ideal bagi pengguna dengan mengimplementasikan basis pengetahuan yang diperoleh, dan mampu mengingatkan pengguna untuk mencukupi kebutuhan airnya. Tingkat aktivitas fisik ditentukan berdasarkan basis pengetahuan yang menggunakan kuesioner GPPAQ serta perhitungan Estimated Energy Requirement (ERR).

\section{METODOLOGI PENELITIAN}

Pelaksanaan penelitian dilakukan sesuai pada Gambar 1 sebagai tahapan metodologi penelitian. Proses pelaksanaan penelitian dilakukan di lingkunan kampus Universitas Kristen Duta Wacana. 


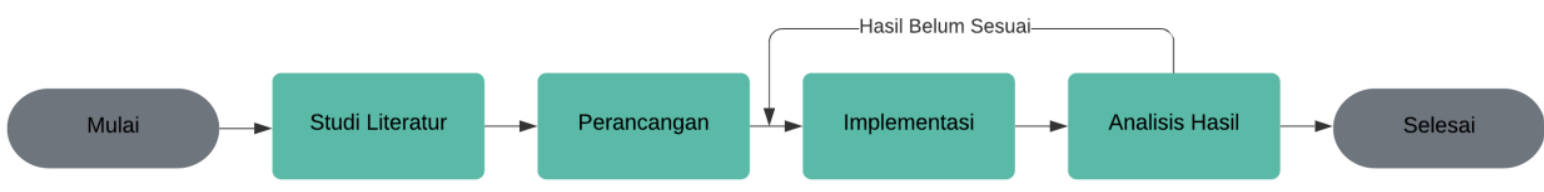

Gambar 1. Alur Metodologi Penelitian

\subsection{Studi Literatur Pengukuran Kebutuhan Air Berdasarkan Tingkat Aktivitas Fisik}

Proses studi literatur ini dilakukan untuk menggali lebih dalam bentuk solusi seperti apa yang tepat bagi penyelesaian permasalahan, target pengguna, serta bagaimana proses implementasi perancangan implementasi yang dapat dilakukan. Hal-hal yang perlu diperhatikan ialah proses penentuan kebutuhan konsumsi air minum pengguna berdasarkan tingkat aktivitas fisik dari pengguna. Metode perhitungan tingkat kebutuhan air bagi tubuh manusia seperti pada tahapan yang dijelaskan pada Gambar 2.Gambar 5

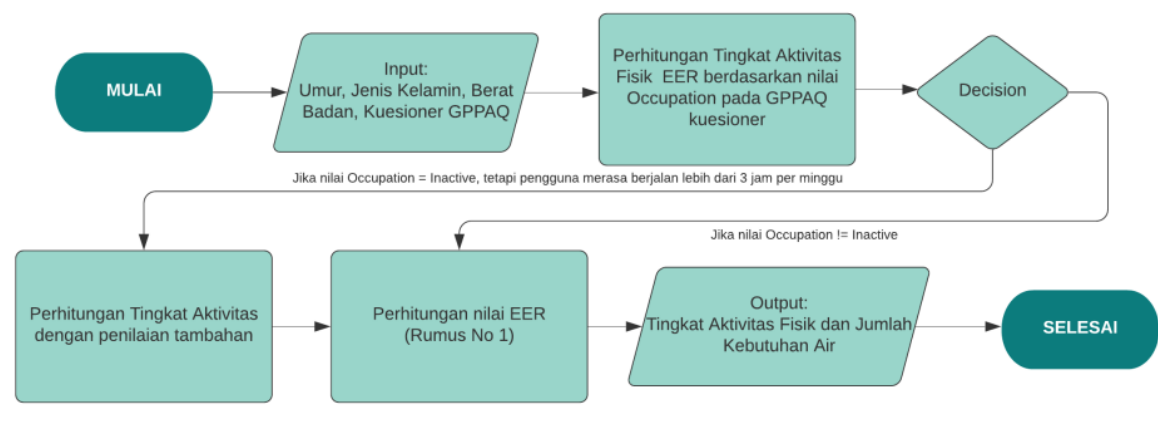

Gambar 2. Flowchart langkah-langkah perhitungan tingkat kebutuhan air bagi tubuh

Perhitungan tingkat aktivitas fisik melalui beberapa pertanyaan pada kuesioner seperti umur, jenis kelamin, berat badan, dan beberapa pertanyaan dari kuesioner GPPAQ. Jenis pertanyaan yang digunakan pada penelitian ini hanya pertanyaan mengenai aktivitas pekerjaan dan aktivitas fisik. Level aktivitas fisik atau physical activity level (PAL) hasil dari GPPAQ nantinya akan dibagi menjadi 4 kategori besar, yaitu inactive, moderately inactive, moderately active, dan active. Penjabaran mengenai masing-masing poinnya dapat diamati pada Gambar 3.

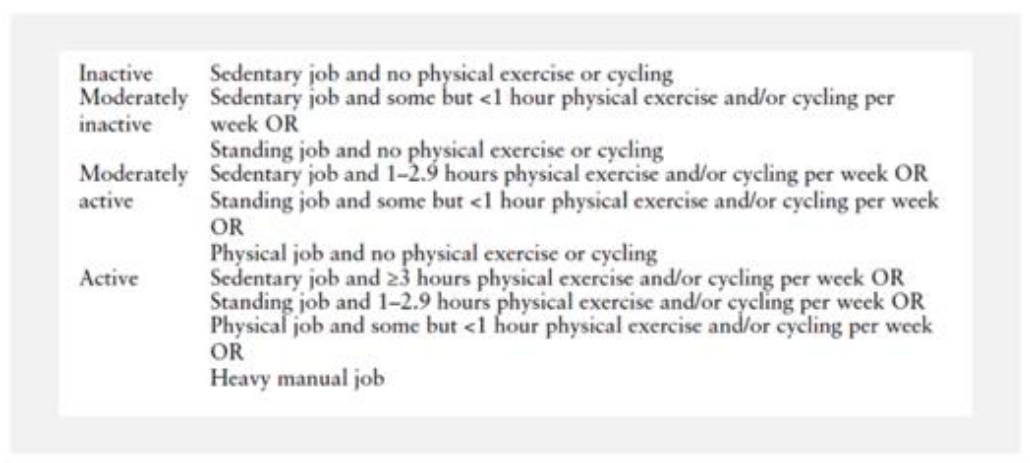

Gambar 3. Pembagian Tingkat Aktivitas Menurut GPPAQ

Cara menilai kuisioner GPPAQ adalah dengan mengisi kolom pekerjaan dan aktivitas fisik khususnya hanya pertanyaan mengenai physical exercise dan cycling, kemudian penilaian menggunakan occupation pada Gambar 4.

\begin{tabular}{|l|c|c|c|c|}
\hline $\begin{array}{l}\text { Physical exercise } \\
\text { and/or cycling (hr/wk) }\end{array}$ & Sedentary & Standing & Physical & Heavy Manual \\
\hline 0 & Inactive & $\begin{array}{c}\text { Moderately } \\
\text { Inactive }\end{array}$ & $\begin{array}{c}\text { Moderately } \\
\text { Active }\end{array}$ & Active \\
\hline Some but $<1$ & $\begin{array}{c}\text { Moderately } \\
\text { Inactive }\end{array}$ & $\begin{array}{c}\text { Moderately } \\
\text { Active }\end{array}$ & Active & Active \\
\hline $1-2.9$ & $\begin{array}{c}\text { Moderately } \\
\text { Active }\end{array}$ & Active & Active & Active \\
\hline$\geq 3$ & Active & Active & Active & Active \\
\hline
\end{tabular}

Gambar 4. Ringkasan cara menilai tingkat aktivitas menurut GPPAQ 
Pertanyaan mengenai kecepatan berjalan atau intensitas berjalan responden pada bagian yang terpisah, karena pada durasi yang lebih dari 3 jam berjalan akan mempengaruhi tingkat aktivitas responden. Namun pertanyaan kecepatan berjalan atau walking pace pada kuisioner GPPAQ, tidak digunakan dikarenakan batasan tidak terlalu jelas dan dapat mengganggu validitas kuisioner. Berdasarkan hal tersebut, terdapat penilaian tambahan untuk menilai tingkat intensitas berjalan yang dapat dilihat pada

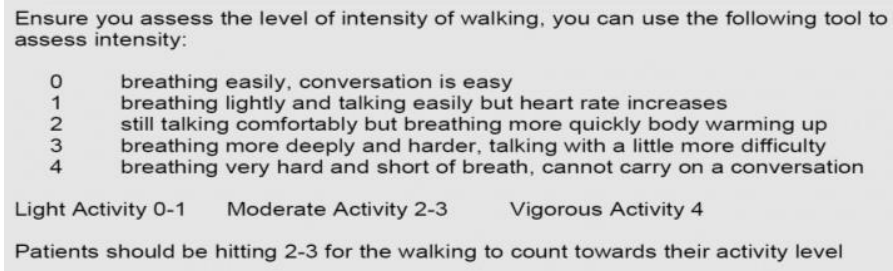

Gambar 5. Penilaian tambahan intensitas berjalan

Gambar 5 adalah detail penilaian untuk menilai tingkat intensitas berjalan pengguna. Penilaian tersebut hanya akan diberikan terhadap pengguna bila diketahui hasil dari perhitungan tingkat aktivitas adalah inactive dan pengguna merasa sering berjalan kaki lebih dari 3 jam per minggu. Perbedaan nama level aktivitas tidak berarti bahwa kriteria penilaiannya tingkat aktivitas akan berbeda. Nama level tingkat aktivitas tetap menggunakan yang ada pada kuisioner GPPAQ. Kategori tingkat aktivitas pada penilaian tambahan light activity sama dengan kategori tingkat aktivitas moderate inactive yang ada pada kuisioner GPPAQ. Sedangkan moderate activity sama dengan moderate active dan vigorous activity sama dengan active. Hal tersebut, berdasarkan dari hasil analisis yang telah dilakukan oleh dr. Josephine Diony Nanda.

Setelah tingkat aktivitas dapat diketahui berdasarkan kuisioner GPPAQ, maka perhitungan kebutuhan air yang ideal bagi tubuh dapat dilakukan dengan menghitung Estimated Energy Requirement (EER) atau estimasi kebutuhan kalori harian. National Research Council USA menetapkan jumlah air yang dibutuhkan manusia per harinya yaitu $1 \mathrm{~mL}$ air/kcal. Dalam penggunaannya, penelitian ini menggunakan $1 \mathrm{~mL}$ air/kcal dikarenakan aktivitas fisik sudah dikelompokkan secara umum menggunakan kuisioner GPPAQ.

Setelah memperoleh data jenis aktivitas fisik dari responden, hal berikutnya yang dilakukan adalah melakukan penghitungan menggunakan rumus "Schofield and WHO energy-requirement equations". Rumus 1 memperlihatkan bagaimana cara menghitung EER:

$$
E E R=B M R \times P A L(\text { constanta })
$$

Keterangan:

EER: Estimated Energi Requirement

BMR: Basal Metabolic Rate

PAL (constanta): Physical Activity Level Constanta

Penentuan nilai Basal Metabolic Rate (BMR) dihitung menggunakan Rumus 2.

$$
\mathrm{BMR}=\left\{\begin{array}{l}
15.1 \times \text { weight }(\mathrm{kg})+692 ; j i k a 18 \geq \text { age } \leq 29 \text { dan gender }=\text { men, } \\
11.5 \times \text { weight }(\mathrm{kg})+873 ; j i k a 30 \geq \text { age } \leq 59 \text { dan gender }=\text { men, } \\
11.9 \times \text { weight }(\mathrm{kg})+700 ; j i k a 60 \leq \text { age dan gender }=\text { men }, \\
14.8 \times \text { weight }(\mathrm{kg})+487 ; j i k a 18 \geq \text { age } \leq 29 \text { dan gender }=\text { women, } \\
8.3 \times \text { weight }(\mathrm{kg})+846 ; j i k a 30 \geq \text { age } \leq 59 \text { dan gender }=\text { women, } \\
11.9 \times \text { weight }(\mathrm{kg})+687 ; j i k a 60 \leq \text { age dan gender }=\text { women, }
\end{array}\right\}
$$

\section{Keterangan}

BMR: Basal Metabolic Rate; Weight: Berat Badan; Age: Umur; Gender: Jenis Kelamin

Nilai konstanta dari setiap level tingkat aktivitas (PAL Constanta) diperoleh dengan mengacu pada Tabe 1. PAL Constanta dapat dilihat pada Tabel 1 dengan memasukan hasil perhitungan tingkat aktivitas fisik dari kuisioner GPPAQ ke dalam Tabel 1.

\begin{tabular}{|c|c|c|c|c|}
\hline $\begin{array}{l}\text { GPPAQ } \\
\text { Result }\end{array}$ & PAL & Description & Men & Women \\
\hline Inactive & Inactive & $\begin{array}{l}\text { Assume sitting most of the day with less than } 2 \text { hours on } \\
\text { their feet. }\end{array}$ & 1.4 & 1.4 \\
\hline $\begin{array}{l}\text { Moderate } \\
\text { Inactive }\end{array}$ & Light & $\begin{array}{l}\text { Assume some daily exercise }- \text { at work or tasks about the } \\
\text { house or garden - with at least } 2 \text { hours on their feet. }\end{array}$ & 1.5 & 1.5 \\
\hline $\begin{array}{l}\text { Moderate } \\
\text { Active }\end{array}$ & Moderate & Assume 6 hours on their feet or regular strenuous exercise & 1.78 & 1.64 \\
\hline
\end{tabular}

Tabel 1. Physical Activity Level (PAL) Constanta [12] 
JURNAL MEDIA INFORMATIKA BUDIDARMA

Volume 5, Nomor 2, April 2021, Page 705-716

ISSN 2614-5278 (media cetak), ISSN 2548-8368 (media online)

Available Online at https://ejurnal.stmik-budidarma.ac.id/index.php/mib

DOI 10.30865/mib.v5i2.2950

\begin{tabular}{|c|c|c|c|c|}
\hline $\begin{array}{l}\text { GPPAQ } \\
\text { Result }\end{array}$ & PAL & Description & Men & Women \\
\hline Active & Heavy & Those in heavy laboring jobs or serious athletes in training. & 2.1 & 1.82 \\
\hline
\end{tabular}

Setelah EER dapat diketahui, maka jumlah kebutuhan air yang dibutuhkan dapat dihitung sesuai dengan tetapan kebutuhan air yaitu $1 \mathrm{~mL} / \mathrm{kcal}$ energi. Contoh perhitungan tingkat kebutuhan air bagi tubuh dapat dengan menyusun sebuah skenario perhitungan. Langkah-langkah perhitungan tingkat kebutuhan air bagi tubuh dapat sesuai pada Gambar 2. Berdasarkan langkah-langkah tersebut, sebagai contoh maka dapat disusun sebuah skenario perhitungan. Seorang ibu berusia 32 tahun dengan berat badan $59 \mathrm{~kg}$ dan telah menjawab pertanyaanpertanyaan pada kuisioner GPPAQ dengan jawaban yang dapat dilihat pada Tabel 2.

Tabel 2. Skenario jawaban kuisioner GPPAQ

\begin{tabular}{ll}
\hline \multicolumn{1}{c}{ Questions } & \multicolumn{1}{c}{ Answer } \\
\hline Job-Related Questions & $\begin{array}{l}\text { Mostly standing with no intense physical effort } \\
\text { (e.g. shop assistance). }\end{array}$ \\
Weekly Physical Exercise-Related Questions & Less than 1 hour. \\
Cycling Routine-Related Questions & Less than 1 hour. \\
\hline
\end{tabular}

Berdasarkan Tabel 2, maka hasil dari perhitungan tingkat aktivitas fisik berdasarkan occupation (Gambar 3) kuisioner GPPAQ adalah moderate active. Setelah mengetahui tingkat aktivitas fisik, maka PAL constanta yang diperlukan untuk menghitung EER untuk skenario tersebut adalah 1,64 berdasarkan pada Tabel 1. Perhitungan EER dengan menggunakan Rumus 1. Dari hasil perhitungan EER didapatkan hasil 2190,548 kcal. Berdasarkan National Research Council USA, kebutuhan air yang harus dikonsumsi dapat dikonversi dari kebutuhan kalori dengan penyetaraan sebesar $1,5 \mathrm{~mL} / \mathrm{kcal}$ energi. Sehingga kebutuhan air dari nilai EER yang didapat yaitu sebesar $3285,822 \mathrm{~mL}$.

\section{HASIL DAN PEMBAHASAN}

\subsection{Rancangan Sistem}

Sistem secara keseluruhan dirancang seperti pada Gambar 6. Sistem dibangun dari 2 komponen utama yaitu Cloud Server Google Firestore, Perangkat Smart Water Dispenser, dan Android Mobile Application.

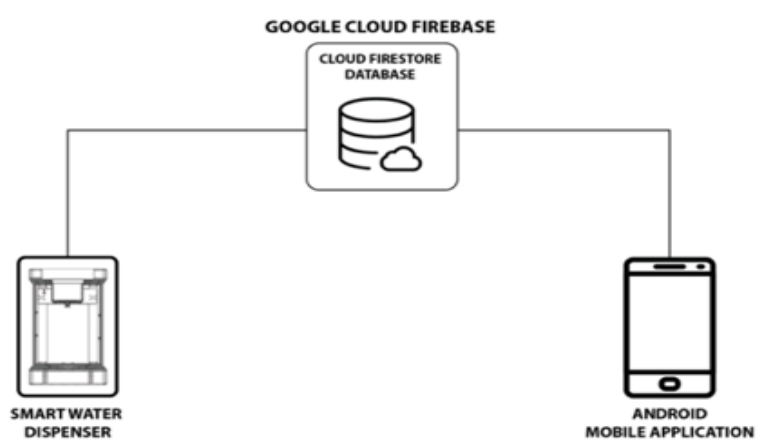

Gambar 6. Arsitektur dan blok diagram sistem

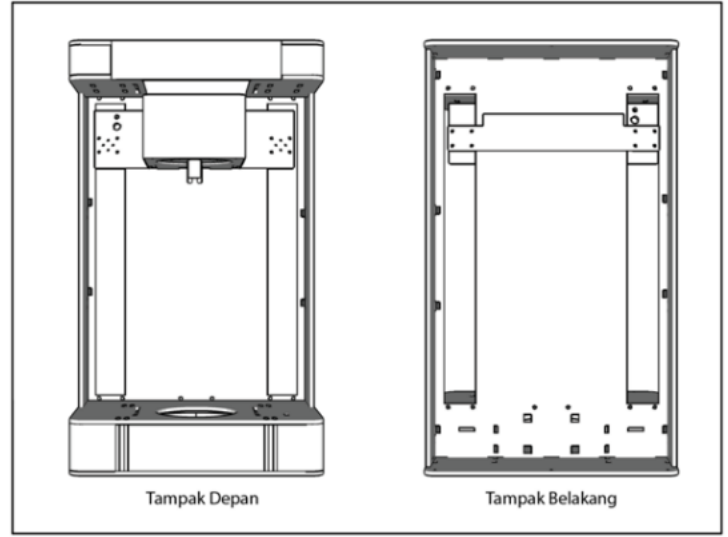

Gambar 7. Rancangan bentuk perangkat smart water dispenser

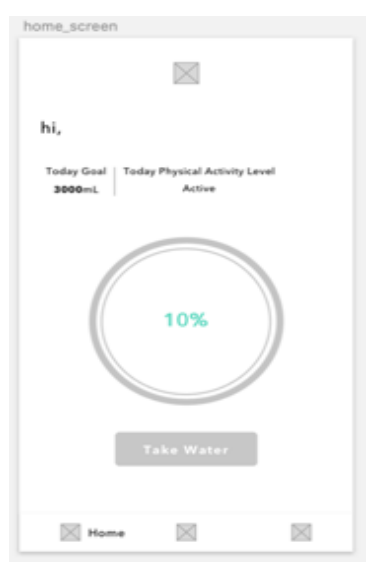

Gambar 8. Halaman utama aplikasi android 
Bagian pertama ialah perancangan cloud server. Google cloud firebase dipilih karena menyediakan layanan rest api dan cloud server yang dibutuhkan sistem pada sistem sistem dapat saling terintegrasi. Penyimpanan data dirancang sesuai dengan standar struktur data dari Google Cloud Firebase dapat dilihat pada Gambar 9. Rancangan penyimpanan data terbagi menjadi dua collection utama yaitu collection users dan hardware. Collection users akan digunakan untuk menyimpan data yang berkaitan dengan pengguna. Users memiliki document berupa userId yang berisi field age, gender, weight, dan name. Collection users juga memiliki tiga nested collection terdiri dari dailyNeeds, notifyData, dan takeWater. Nested collection dailyNeeds memiliki document dateNow berisi field create-date, day-name, physical-activity, today-goal, dan today-intake. Nested collection notifyData memiliki document index berisi field hour, id, dan minute. Nested collection takeWater memiliki document dateNow berisi field date-today dan memiliki nested collection hours. Nested collection hours memiliki document timeNow berisi field hours dan intake-value. Collection hardware memiliki document vZumatKowSRwFqliczmH berisi field bottle-status, current-mode, filling-status, intake-value, requeststatus, dan response-code. Collection tersebut digunakan untuk menyimpan data interaksi dalam proses pengambilan air yang dilakukan pengguna pada smart water dispenser melalui aplikasi android.

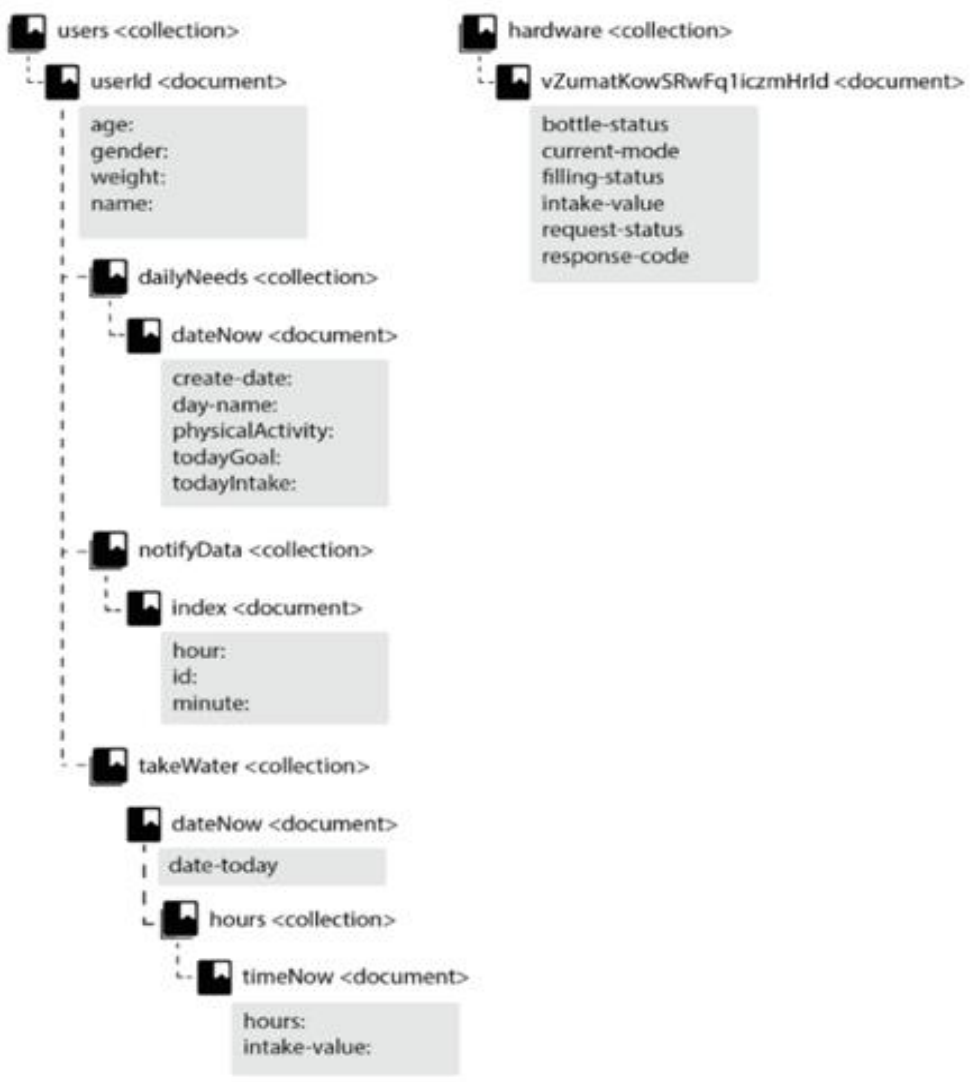

Gambar 9. Rancangan penyimpanan data

Bagian kedua adalah perancangan perangkat smart water dispenser yang dilengkapi dengan bentukbentuk mekanisme yang bertujuan menjalankan fitur pengisian air secara otomatis pada botol. Bentuk perangkat smart water dispenser dapat dilihat pada Gambar 7 yang merupakan gambar tampak depan dan tampak belakang perancangan bentuk perangkat smart water dispenser. Bagian ketiga adalah perancangan antarmuka aplikasi android. Halaman home_screen sebagai halaman utama atau landing page pada aplikasi android. Gambar 8 adalah halaman home_screen. Halaman tersebut akan menampilkan informasi meliputi jumlah kebutuhan air harian, tingkat aktivitas harian, informasi proses dalam memenuhi kebutuhan air harian, dan menampilkan nama pengguna.

\subsection{Hasil Implementasi Sistem}

Tahapan yang dilakukan pada proses implementasi ialah proses pembangunan smart water dispenser. Fitur-fitur yang difokuskan pada perangkat ini ialah perangkat dapat berkomunikasi dan bertukar data dengan google firestore, perangkat juga dapat menentukan jumlah air yang dikeluarkan sesuai dengan besar botol air yang digunakan secara otomatis. Selain itu beberapa perangkat sensor dan pompa air yang harus diujicoba terlebih dahulu agar tingkat kepresisian dalam menghitung jumlah air yang dikelurakan. Selanjutnya proses impelemtasi aplikasi android beserta struktur data pada Google Firestore. Proses implementasi pada akhirnya dari setiap bagian harus dijalankan secara bersamaan agar fungsionalitas sistem dapat berjalan dengan baik. 


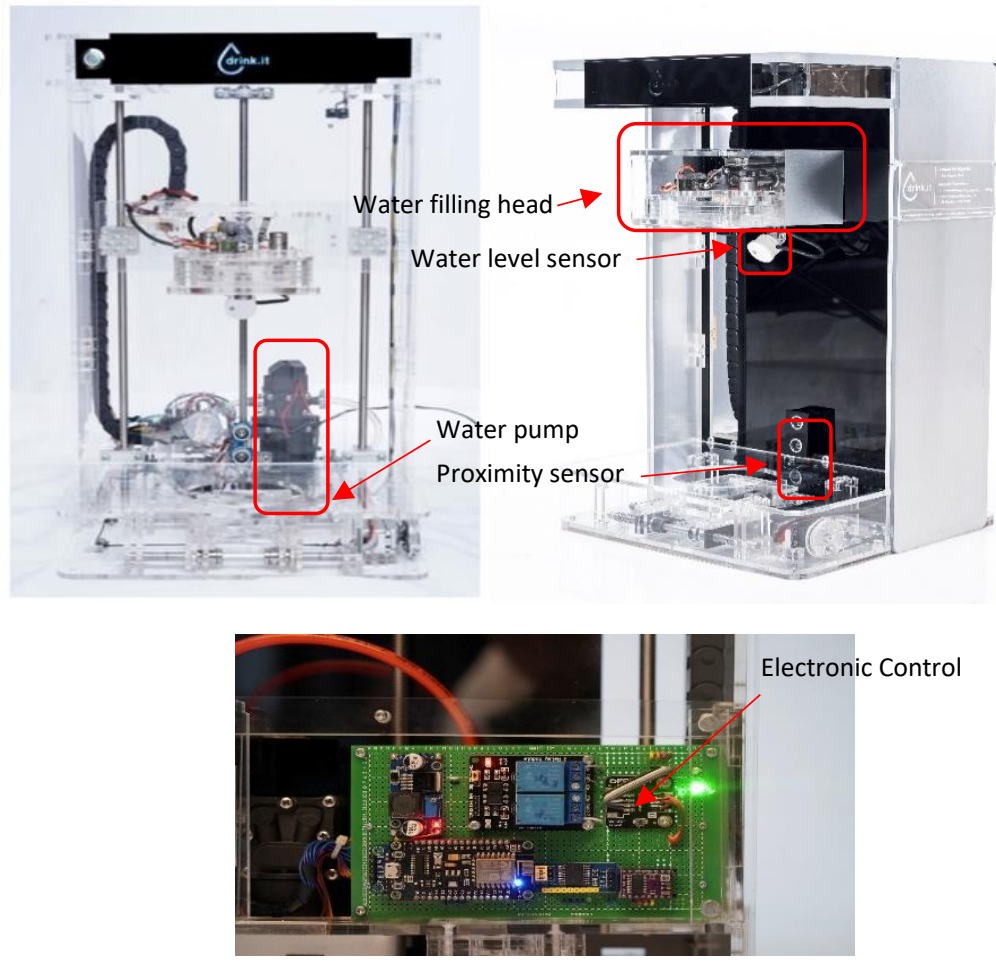

Gambar 10. Perangkat smart water dispenser

Implementasi sistem dibagi menjadi tiga bagian yang saling terintegrasi yaitu perangkat smart water dispenser, aplikasi android, dan cloud server. Implementasi perangkat smart water dispenser mulai dari proses assembly bentuk utama, proses assembly bentuk mekanisme pengisian air otomatis, dan proses wiring installation perangkat keras yang terdiri dari microcontroller, sensor, dan actuator. Gambar 10 adalah bentuk secara fisik perangkat smart water dispenser.

Implementasi aplikasi android mulai dari implementasi antarmuka aplikasi, implementasi metode perhitungan tingkat kebutuhan air dan implementasi notification service. Gambar 11a adalah halaman input pengguna untuk mengisi data diri yang dibutuhkan oleh sistem dalam proses perhitungan tingkat kebutuhan air. Gambar 11b adalah halaman home_screen aplikasi android yang juga sebagai landing page. Halaman tersebut menampilkan informasi seperti nama pengguna, jumlah kebutuhan air harian, tingkat aktivitas, progres pengguna dalam memenuhi kebutuhan air harian, dan terdapat tombol take water sebagai tombol untuk melakukan proses pengambilan air pada perangkat smart water dispenser. Kemudian implementasi metode perhitungan tingkat kebutuhan air yang telah dibahas pada Sub Bab A. Terdapat tiga kategori pertanyaan yaitu pertanyaan mengenai aktivitas pekerjaan, aktivitas fisik seperti olahraga, dan aktivitas bersepeda.

Gambar 12a adalah pertanyaan terkait aktivitas pekerjaan, Gambar 12b adalah pertanyaan terkait aktivitas fisik seperti olahraga, dan Gambar 12c adalah pertanyaan terkait aktivitas bersepeda pengguna. Dari ketiga pertanyaan tersebut akan diperoleh tingkat aktivitas fisik berdasarkan occupation dari GPPAQ. Tingkat aktivitas perlu ditentukan karena termasuk faktor penentu tingkat kebutuhan air harian. Setelah tingkat aktivitas dapat diketahui, perhitungan EER dapat dilakukan.
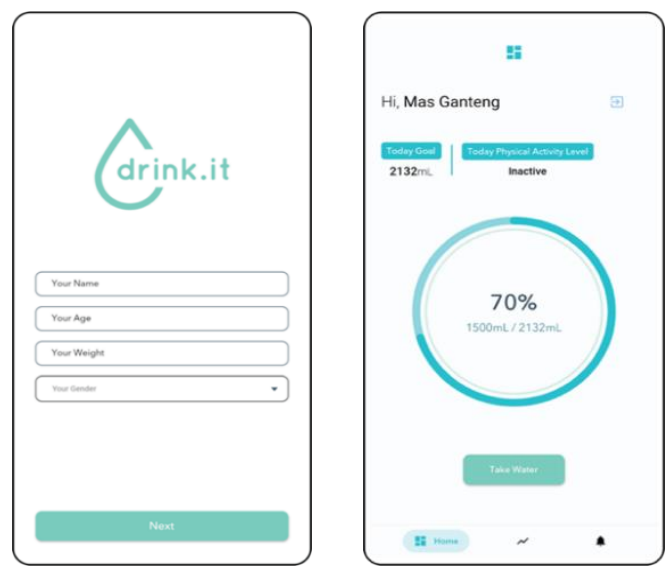

Gambar 11. (a) Profile_screen (b) home_screen 
ISSN 2614-5278 (media cetak), ISSN 2548-8368 (media online)

Available Online at https://ejurnal.stmik-budidarma.ac.id/index.php/mib DOI 10.30865/mib.v5i2.2950
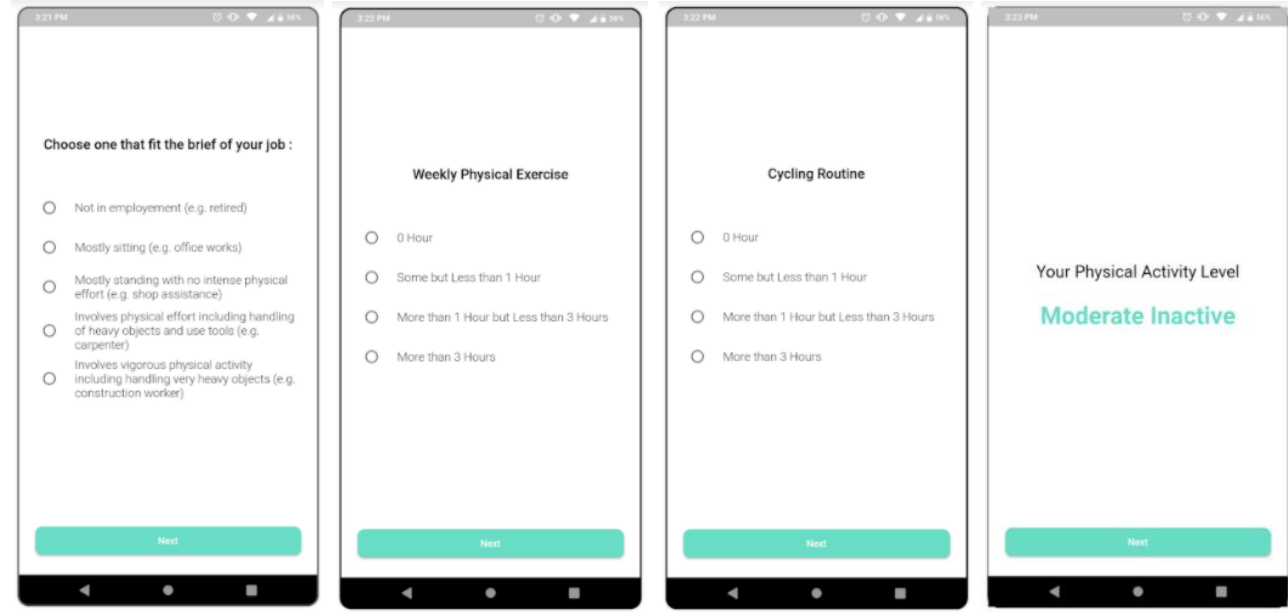

Gambar 12. (a) Jobquestion_screen (b) exercisequestion_screen (c) cyclingquestion_screen (d) activitylevel_screen

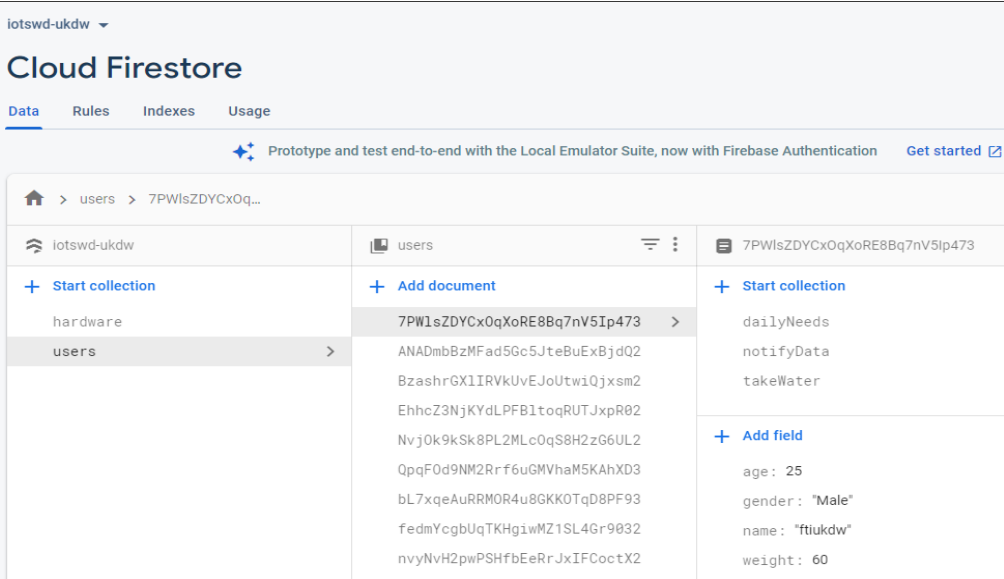

Gambar 13. Google cloud firestore console

Bagian ketiga adalah implementasi cloud server dan REST API dengan menggunakan layanan yang telah disediakan oleh google cloud firebase. Google cloud firestore digunakan sebagai cloud server untuk penyimpanan data pada sistem. Gambar 13 adalah tampilan console pada google cloud firestore.

REST API dibuat dengan menggunakan layanan REST API yang disediakan oleh google cloud firebase. REST API URL dibutuhkan perangkat smart water dispenser agar microcontroller dapat terintegrasi dengan cloud server. Gambar 14 adalah hasil dari pembuatan REST API URL yang berisi data dengan format JSON. Untuk mendapatkan data JSON pada REST API URL, microcontroller menggunakan method GET, sedangkan untuk memperbarui data menggunakan method PATCH pada http request.

\section{REST API URL :}

https:/firestore.googleapis.com/v1/projects/skripsi-app-1e806/databases/(default)/documents/hardware/vZumatKowSRwFq1 iczmH

\section{Gambar 14. REST API URL}

\subsection{Pengujian dan Pembahasan Fungsionalitas Perangkat Smart Water Dispenser}

Proses pengujian dilakukan terhadap fungsionalitas perangkat smart water dispenser serta aplikasi android yang digunakan oleh pengguna. Pengujian fungsionalitas dari perangkat smart water dispenser dilakukan dengan menggunakan system checking checklist. Sedangkan Pengujian sistem kepada pengguna (usability testing) menggunakan metode cognitive walkthrough yang memungkinkan pengguna untuk mempelajari tugas-tugas dalam sistem. Metode ini melakukan pengamatan dan pengujian secara langsung kepada pengguna yang ditargetkan bertindak sebagai subjek uji. Proses pengujian ini menggunakan 3 orang pengguna dengan rentang umur 20 - 30 tahun. Pengguna akan diberikan beberapa tugas dalam penggunaan sistem ini, baik dari sisi aplikasi android, maupun penggunaan smart water dispenser. Proses pengamatan dan cheklist dilakukan dalam melihat keberhasilan pengguna dalam menggunakan sistem ini. Terbatasnya jumlah pengguna pada pengujian ini dikarenakan pengujian dilakukan hanya pada uji fungsionalitas setiap komponen dan bekerja dengan baik. 
Pengujian dilakukan dengan menguji setiap komponen fungsionalitas perangkat smart water dispenser berdasarkan system testing checklist. Pengujian dilakukan dengan menggunakan 4 botol uji yang memiliki dimensi yang berbeda. Tabel 4 adalah hasil dari pengujian dengan menggunakan system testing checklist memperlihatkan bahwa fungsionalitas perangkat smart water dispenser sudah berjalan sesuai dengan yang diharapkan, namun terdapat catatan perbaikan yang diperlukan agar fungsionalitas dapat bekerja lebih baik. Linear motion track pada dynamic mechanism memerlukan perbaikan dengan mengganti linear motion track yang lebih presisi sehingga pergerakan mekanisme menjadi lebih lancar karena berat dari bentuk dynamic mechanism dapat menghambat pergerakan mekanisme jika linear motion track tidak presisi yang menyebabkan overheat pada stepper motor karena kinerja stepper motor menjadi lebih berat. Untuk mengatasi overheat diperlukan cut-off voltage yang berfungsi untuk membatasi kinerja stepper motor ketika terjadi overheat.

Tabel 4. System testing checklist

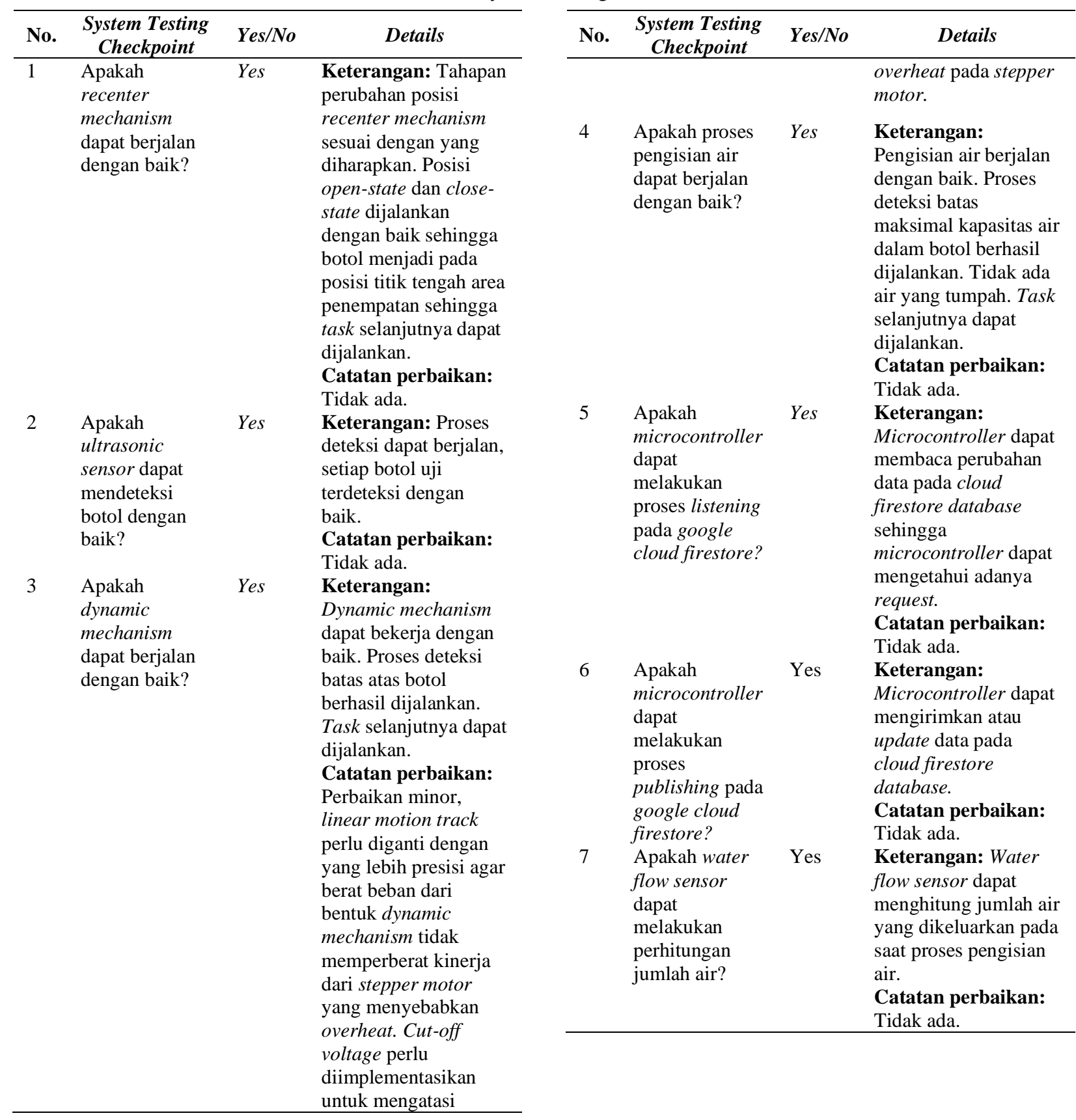

\subsection{Analisis dan Pengujian Tingkat Presisi Water Flow Sensor}

Pengujian dilakukan dengan membandingkan hasil perhitungan jumlah air pada water flow sensor dengan jumlah aktual air yang diukur dengan menggunakan gelas ukur. Tabel 5 memperlihatkan perbedaan data antara perhitungan pada water flow sensor dan jumlah aktual air. Dari hasil tersebut, rata-rata tingkat presisi adalah 92,6\%. Perbedaan data tidak begitu signifikan, namun akan berbeda ketika hasil perhitungan water flow sensor digunakan sebagai data intake record pengguna. Perbedaan perhitungan akan menjadi sangat signifikan dan hal 
tersebut dapat mempengaruhi validitas data progress pengguna dalam mencukupi kebutuhan air yang dibutuhkan.

Tabel 5. Pengujian tingkat presisi water flow sensor

\begin{tabular}{ccc}
\hline Water Flow Sensor & $\begin{array}{c}\text { Jumlah Aktual } \\
\text { Air }\end{array}$ & Tingkat Presisi \\
\hline $100 \mathrm{~mL}$ & $100 \mathrm{~mL}$ & $100 \%$ \\
$150 \mathrm{~mL}$ & $170 \mathrm{~mL}$ & $88,2 \%$ \\
$200 \mathrm{~mL}$ & $210 \mathrm{~mL}$ & $90,9 \%$ \\
$250 \mathrm{~mL}$ & $270 \mathrm{~mL}$ & $89,3 \%$ \\
$300 \mathrm{~mL}$ & $320 \mathrm{~mL}$ & $92,3 \%$ \\
$400 \mathrm{~mL}$ & $450 \mathrm{~mL}$ & $94,6 \%$ \\
$450 \mathrm{~mL}$ & $490 \mathrm{~mL}$ & $90,9 \%$ \\
$500 \mathrm{~mL}$ & $540 \mathrm{~mL}$ & $91,8 \%$ \\
\hline
\end{tabular}

\subsection{Analisis dan Pengujian Perhitungan Tingkat Kebutuhan Air}

Pengujian dilakukan dengan membandingkan hasil perhitungan tingkat kebutuhan air dengan menggunakan data uji. Berdasarkan Tabel 6 dapat diamati bahwa tidak ada perbedaan antara perhitungan sistem dan manual. Berdasarkan hal tersebut, maka implementasi metode perhitungan tingkat kebutuhan air berhasil dilakukan dengan baik. Tabel 6 dapat diamati perbedaan yang signifikan pada data uji. Data uji nomor 1 dan nomor 22 sebagai contoh perbedaan yang sangat signifikan. Hal tersebut disebabkan oleh perbedaan tingkat aktivitas, umur, berat badan, dan jenis kelamin.

Tabel 6. Perhitungan tingkat kebutuhan air

\begin{tabular}{cccc}
\hline $\begin{array}{c}\text { No. } \\
\text { Data } \\
\text { Uji }\end{array}$ & $\begin{array}{c}\text { Tingkat Aktivitas } \\
\text { Fisik }\end{array}$ & $\begin{array}{c}\text { Perhitungan } \\
\text { Sistem }\end{array}$ & $\begin{array}{c}\text { Perhitungan } \\
\text { Manual }\end{array}$ \\
\hline 1 & Active & $3863 \mathrm{~mL}$ & $3863 \mathrm{~mL}$ \\
2 & Inactive & $2494 \mathrm{~mL}$ & $2494 \mathrm{~mL}$ \\
3 & Moderate Active & $2871 \mathrm{~mL}$ & $2871 \mathrm{~mL}$ \\
4 & Active & $2287 \mathrm{~mL}$ & $2287 \mathrm{~mL}$ \\
5 & Inactive & $1635 \mathrm{~mL}$ & $1635 \mathrm{~mL}$ \\
6 & Moderate & $2063 \mathrm{~mL}$ & 2063 \\
& Inactive & & \\
\hline
\end{tabular}

\subsection{Analisis dan Pengujian Keseluruhan Sistem}

Tabel 7. Pertanyaan pada cognitive walkthrough

\begin{tabular}{cl}
\hline Id & \multicolumn{1}{c}{ Question } \\
\hline Q1 & Berdasarkan informasi yang tersedia apakah pengguna mengerti bagaimana memulai task? \\
Q2 & $\begin{array}{l}\text { Berdasarkan respon dari sistem, apakah pengguna mengerti bahwa telah melakukan hal } \\
\text { yang benar dalam menjalankan task dan mengerti bahwa pengguna membuat kemajuan } \\
\text { progress terhadap tujuan dari task yang ingin dicapai? }\end{array}$ \\
Q3 & Apakah pengguna mampu menyelesaikan task? \\
\hline
\end{tabular}

Tabel 8. Cognitive walkthrough task list

\begin{tabular}{|c|c|c|}
\hline Task & Q1 Q2 & Q3 \\
\hline Pendaftaran Akun \& data diri & & \\
\hline Membuat daftar notifikasi pertama & & \\
\hline Menjawab kuisioner & & \\
\hline Ambil Air Mode Otomatis & & \\
\hline Ambil Air Mode Manual & & \\
\hline $\begin{array}{l}\text { Mengatur ulang daftar notifikasi setelah halaman home } \\
\text { ditampilkan }\end{array}$ & & \\
\hline
\end{tabular}

Cognitive walkthrough bertujuan untuk mengidentifikasi permasalahan pada sistem yang dapat terjadi berdasarkan pertanyaan dan task pada Tabel 7 dan tabel 8. Cognitive walkthrough dilakukan dengan menguji pada 3 responden dan mengamati proses pengguna dalam menyelesaikan setiap task. Pada pengujian ini, jumlah minimal responden tidak ditentukan karena pengujian dilakukan secara deep ovbservasion atau pengamatan 
mendalam pada setiap responden ketika menjalankan task, namun kriteria responden ditentukan pada pengujian ini. Kriteria responden adalah responden yang belum pernah menggunakan sistem dan memiliki kemampuan berbahasa inggris karena sistem dibangun versi bahasa inggris.

Analisis dari hasil pengujian keseluruhan sistem dengan menggunakan metode cognitive walkthrough pada tiga responden adalah sebagai berikut:

1. Setiap responden dapat menyelesaikan task pendaftaran akun dengan baik.

2. Pada task membuat daftar notifikasi, responden 1 memerlukan informasi tamabah untuk memahami tombol mana yang berfungsi untuk membuat daftar notifikasi dengan bertanya pada observer, sedangkan responden 2 tidak dapat menyelesaikan task tersebut karena tombol "+" dan tombol "Next" pada antarmuka createfirstnotify_screen membingungkan pengguna. Responden 3 dapat menjalakan task dengan baik.

3. Setiap responden dapat menyelesaikan task menjawab kuisioner dengan baik.

4. Setiap responden dapat menyelesaikan task pengambilan air otomatis dengan baik.

5. Instruksi pada ambil air mode manual tidak jelas. 2 responden tidak dapat menyelesaikan

6. Task mengatur ulang daftar notifikasi setelah halaman home_screen ditampilkan dapat diselesaikan oleh setiap responden dengan baik.

\section{KESIMPULAN}

Berdasarkan hasil pengujian dan analisis sistem, maka dapat disimpulkan bahwa perangkat smart water dispenser berhasil mengimplementasikan teknologi internet of things berdasarkan pada hasil pengujian fungsionalitas perangkat menggunakan system testing checklist. Basis pengetahuan perhitungan tingkat kebutuhan air juga dapat diimplementasikan pada sistem. Sistem smart water dispenser dapat membantu pengguna dalam proses memenuhi kebutuhan air dengan memberikan informasi jumlah air yang telah pengguna konsumsi dari perangkat smart water dispenser serta dapat memberikan pemberitahuan jika pengguna lupa mengkonsumsi air dalam jeda waktu yang lama. Sistem masih memiliki beberapa kekurangan yaitu tingkat presisi dari perhitungan jumlah air pada water flow sensor hanya 92,6\%, sehingga hal tersebut dapat mempengaruhi proses pengguna dalam mencukupi kebutuhan air yang dibutuhkan. Di sisi lain, permasalahan tingkat kepresisian dari water flow sensor memungkinkan untuk diatasi dengan mengatur ulang calibration factor dan menerapkan linear regression pada perhitungan water flow sensor. Fitur mode manual dalam pengambilan air pada perangkat smart water dispenser sulit untuk dipahami pengguna. Hal tersebut terjadi karena informasi petunjuk tidak direpresentasikan dalam bentuk grafis, sehingga pengguna susah untuk memahami maksud dari instruksi tersebut.

\section{REFERENCES}

[1] W. F. Clark et al., "The chronic kidney disease water intake trial: Protocol of a randomized controlled trial," Can. J. Kidney Heal. Dis., vol. 4, pp. 1-11, 2017.

[2] G. Aphamis, P. S. Stavrinou, E. Andreou, and C. D. Giannaki, "Hydration status, total water intake and subjective feelings of adolescents living in a hot environment, during a typical school day," Int. J. Adolesc. Med. Health, Apr. 2019.

[3] J. D. Stookey and J. König, "Describing water intake in six countries: results of Liq.In7 surveys, 2015-2018," Eur. J. Nutr., vol. 57, no. Suppl 3, pp. 35-42, Jun. 2018.

[4] T. Maelani and W. H. Cahyati, "Higeia Journal of Public Health," Higeia J. Public Heal. Res. Dev., vol. 1, no. 3, pp. 84-94, 2018.

[5] Y. Yen, Z. Chou, M. Hou, and X. Wang, "The design of intelligent water supply device based on MCU," in ICEIEC 2015 - Proceedings of 2015 IEEE 5th International Conference on Electronics Information and Emergency Communication, 2015, pp. 388-391.

[6] R. L. Singgeta and R. Rumondor, "RANCANG BANGUN DISPENSER OTOMATIS MENGGUNAKAN SENSOR ULTRASONIK BERBASIS MIKROKONTROLLER ATMEGA2560,” J. Ilm. Realt., vol. 14, no. 1, pp. 31-36, Apr. 2018.

[7] A. T, S. Jadhav, and S. Mahamani, "Smart Water Dispenser and Monitoring Water Level in IoT and Android Environment," Int. J. Comput. Sci. Eng., vol. 7, no. 5, pp. 810-814, 2019.

[8] A. N. Fathoni, N. Hudallah, R. D. M. Putri, K. Khotimah, T. Rijanto, and M. Ma'Arif, "Design Automatic Dispenser for Blind People based on Arduino Mega using DS18B20 Temperature Sensor," in Proceeding - 2020 3rd International Conference on Vocational Education and Electrical Engineering: Strengthening the framework of Society 5.0 through Innovations in Education, Electrical, Engineering and Informatics Engineering, ICVEE 2020, 2020.

[9] A. L. Madana and L. Sadath, "IoT Applications in Automated Water Level Detections," in Proceedings of International Conference on Intelligent Engineering and Management, ICIEM 2020, 2020, pp. 401-407.

[10] Z. Chen and Y. He, "A smart power saver based on composite switch and self-learning fuzzy control for drinking water dispenser," in 2016 IEEE International Conference on Power and Renewable Energy, ICPRE 2016, 2017, pp. $275-278$.

[11] Benny dkk., ""SMART DISPENSER" Dispenser Pintar Dengan Pengontrol Suhu Dan Penghemat Energi.," POLITEKNOLOGI VOL. 14 No. 2 MEI 2015., vol. 14, no. 2, 2015. 
[12] W. Z. Cheng, R. G. Cheng, and S. Y. Chou, "Power-saving for IoT-enabled water dispenser system," 2019 42nd Int. Conf. Telecommun. Signal Process. TSP 2019, pp. 736-739, 2019.

[13] F. Khair, "Internet Of Things, Sejarah, Teknologi Dan Penerapannya : Review," J. Ilm. Teknol. Inf., vol. IV, no. 3, pp. 62-66, 2015

[14] S. Somantri, I. Yustiana, and A. Nugraha, "Electrical Consumption Monitoring and Controlling System Based on IoT and Mobile Application," in 7th International Conference on ICT for Smart Society: AIoT for Smart Society, ICISS 2020 - Proceeding, 2020.

[15] B. E. Ainsworth, "How do i measure physical activity in my patients? Questionnaires and objective methods," British Journal of Sports Medicine, vol. 43, no. 1. Br J Sports Med, pp. 6-9, Jan-2009.

[16] D. M. Sesar, F. Fakhrurrazy, and R. Panghiyangani, "Hubungan Tingkat Aktivitas Fisik dengan Fungsi Kognitif pada Lansia di Panti Sosial Tresna Wredha Kalimantan Selatan," Mutiara Med. J. Kedokt. dan Kesehat., vol. 19, no. 1, pp. 27-31, 2019

[17] S. Ahmad et al., "Evaluation of reliability and validity of the General Practice Physical Activity Questionnaire (GPPAQ) in 60-74 year old primary care patients Service organization, utilization, and delivery of care," BMC Fam. Pract., vol. 16, no. 1, Sep. 2015. 